\section{In Vitro Propagation of Apios americana}

\author{
E.R.M. Wickremesinhe, W.J. Blackmon, and B.D. Reynolds \\ Department of Horticulture, Louisiana Agricultural Experiment Station, \\ Louisiana State University Agricultural Center, Baton Rouge, LA 70803
}

Additional index words. tissue culture, groundnut, tuber, legume

\begin{abstract}
Shoot proliferation from axillary buds of Apios americana Medikus (apios, groundnut) was obtained on a modified Murashige and Skoog (MS) medium supplemented with $2.22 \mu \mathrm{M}$ BAP, $0.5 \mu \mathrm{M}$ IBA, and 3.0 $\mu_{M} \mathrm{GA}_{3}$. Existed shoots rooted on MS basal medium. About $60 \%$ of the rooted plants were successfully established in soil. Chemical names used: $1 \mathrm{H}$ - indole-3-butanoic acid (IBA). gibberellic acid $\left(\mathrm{GA}_{3}\right)$, $\mathrm{N}^{6}$-benzylaminopurine (BAP).
\end{abstract}

Apios americana (apios, groundnut) is a nitrogen-fixing, viney legume native to North America that is being domesticated as a tuber crop for human consumption (Blackmon and Reynolds, 1986; Reynolds et al., 1990; Wickremesinhe et al., 1990).

The objective of this study was to develop an apios micropropagation system via proliferation of axillary buds that would facilitate rapid increase of superior genotypes, maintenance of disease-free material, and the production of polyploids using colchicine.

Seeds were soaked in $5.25 \%$ sodium hypochlorite (100\% Clorox) for $15 \mathrm{~min}$, washed three times in sterile distilled water, and grown in culture tubes containing $10 \mathrm{ml}$ of water agar (7\% TC agar) or in Magenta GA-7 vessels (Magenta Corp., Chicago) containing 20 $\mathrm{ml}$ of water agar. Seeds were incubated under continuous light $\left(\approx 60 \mu \mathrm{mol} \cdot \mathrm{s}^{-1} \cdot \mathrm{m}^{-2}\right)$ at $26 \mathrm{C}$ for germination. Tubes with any indication of contamination were discarded.

When seedlings were 10 to $12 \mathrm{~cm}$ in length, nodal epicotyl sections containing two ad-

Received for publication 7 Aug. 1989. The cost of publishing this paper was defrayed in part by the payment of page charges. Under postal regulations, this paper therefore must be hereby marked advertisement solely to indicate this fact. jacent nodes were excised, and two two-noded seedling explants were placed in 250 -ml widemouthed Erlenmeyer flasks containing $40 \mathrm{ml}$ of SMB medium that consisted of Murashige and Skoog (1962) salt base supplemented with (all in mg.liter ${ }^{-1}$ ) 20,000 sucrose, 100 myoinositol, 2 thiamine $\cdot \mathrm{HCl}, 2 \mathrm{D}$-pantothenic acid, 1pyridoxine, and 1 nicotinic acid. To SMB were added $0.5 \mu \mathrm{M}$ IBA and a range of BAP/ $\mathrm{GA}_{3}$ combinations (see Fig. 1). The flasks were covered with aluminum foil, sealed with parafilm, and placed on an orbital shaker at 30 to $40 \mathrm{rpm}$ under continuous light with 70 to $80 \mu \mathrm{mol} \cdot \mathrm{s}^{-1} \cdot \mathrm{m}^{-2}$ of cool-white fluorescent light at $\approx 29 \mathrm{C}$. The number of shoots ( $4 \mathrm{~cm}$ or longer) was recorded at the end of 4 weeks. Each treatment in an experiment was replicated five times and experiments were repeated at least three times. Internodal sections were used as controls.

Proliferated shoots were excised when they were $4 \mathrm{~cm}$ or longer and placed in $25 \times$ 200-ml culture tubes containing $4 \mathrm{ml}$ SMB medium for root induction. Rooting could also be achieved on solid medium and in the presence of 2.5 or $0.5 \mu \mathrm{M}$ IBA (Wickremesinhe, 1988). Tubes were covered with plastic caps and incubated under a 12-hr photoperiod with 60 to $70 \mu \mathrm{mol} \cdot \mathrm{s}^{-1} \cdot \mathrm{m}^{-2}$ of cool-white fluorescent light at $\approx 26 \mathrm{C}$.

Shoots that had at least one well-developed 3- to 5-cm-long root were washed in water, acclimatized, and transferred to the

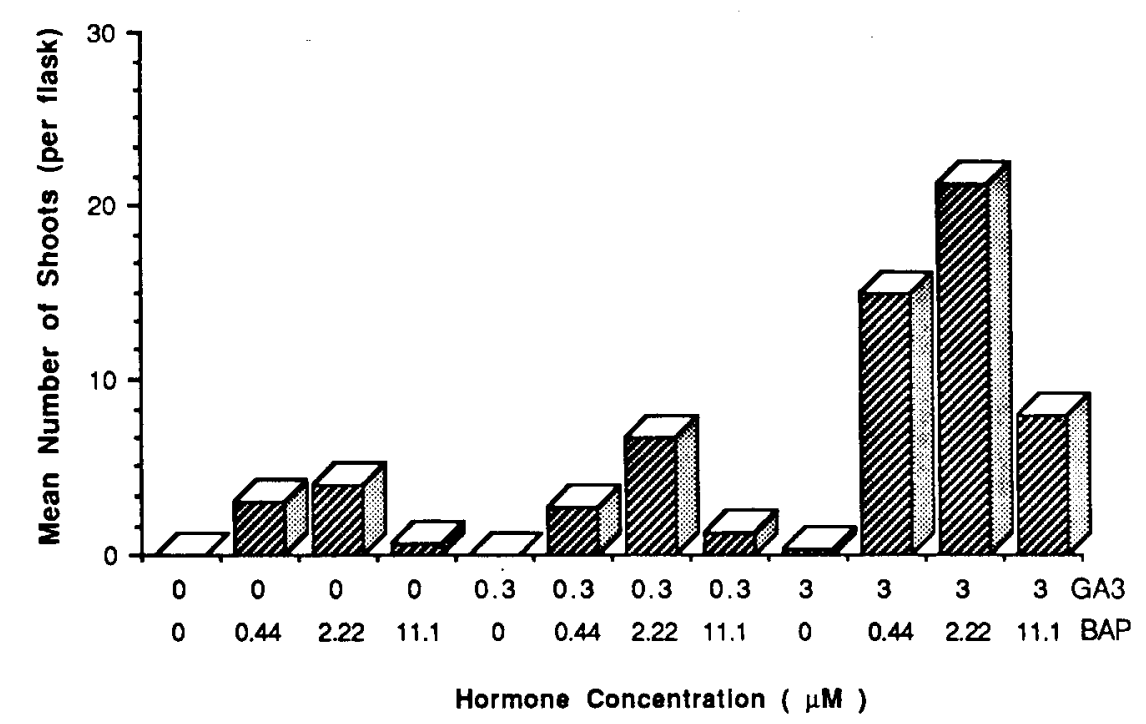

Fig. 1. Shoot proliferation from seedling-derived two-noded explants of $A$. americana on SMB medium plus $0.5 \mu \mathrm{M}$ IBA after 4 weeks in culture. Each flask contained two two-noded explants. 


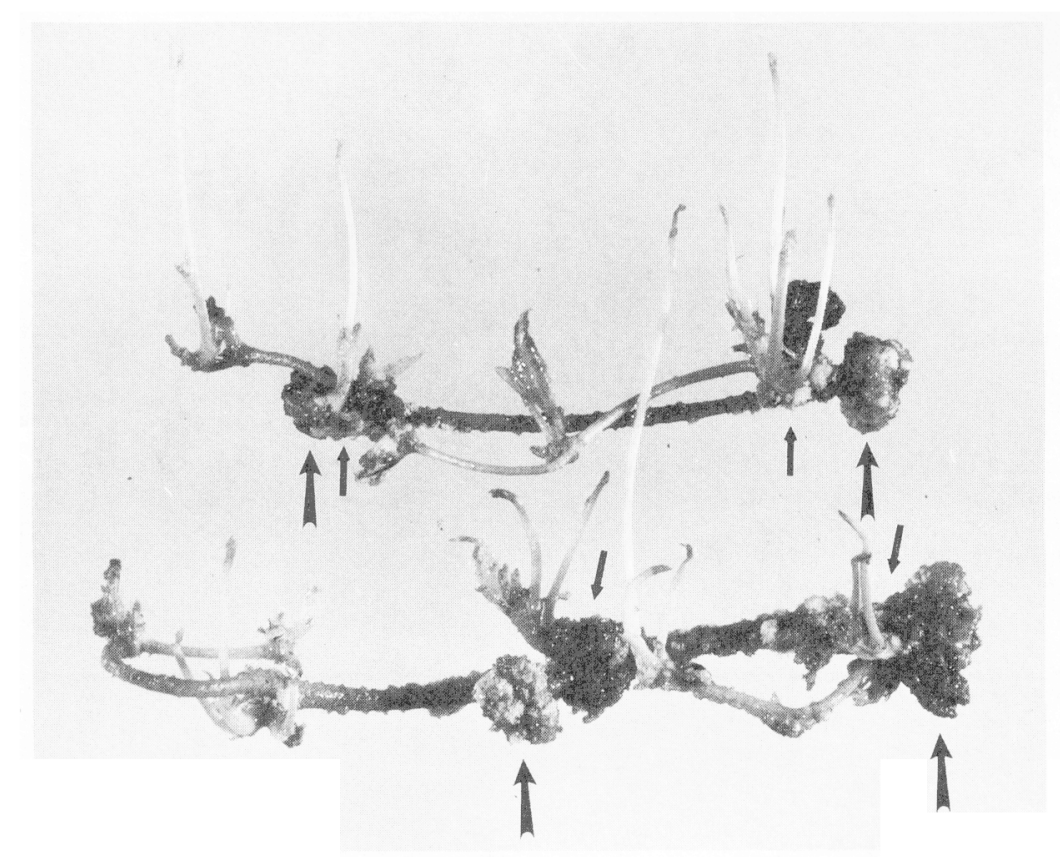

Fig. 2. Shoot multiplication via proliferation of the axillary buds on two two-noded epicotyl explants of $A$. americana placed on SMB-2 medium for 2 weeks: $(\rightarrow)$ Explants, $(\rightarrow)$ nodes of original explant. A total of 18 shoots can be seen. $(\times 1.6)$

greenhouse as described by Wickremesinhe et al. (1990). About $60 \%$ of the rooted plants were successfully transferred to soil.

During preliminary experiments, singlenoded and two-noded explants exhibited very slow growth when placed on solid media; when placed in liquid media, rapid proliferation of the axillary buds was observed. Two-noded explants grew faster than singlenoded explants, and the presence of two twonoded explants in each flask also increased the number of shoots obtained per explant (preliminary observations). SMB media containing $2.22 \mu \mathrm{M}$ BAP, $0.5 \mu \mathrm{M}$ IBA, and 3.0 $\mu \mathrm{M} \mathrm{GA}$ produced the greatest number of 4 $\mathrm{cm}$ or longer shoots when two two-noded explants were used (Fig. 1). Each node produced five shoots after 4 weeks in culture (Fig. 2). No shoots proliferated in the absence of BAP. Extending the duration of the culture period longer than 4 to 5 weeks did not increase the total number of usable shoots. Although shoots were produced after 5 weeks, the oldest shoots began to senesce. In subsequent repetitions, a range of 19 to 29 shoots

was obtained per flask (each flask contained two two-noded explants).

To evaluate the potential for serial proliferation, 10 two-noded explants were harvested per flask after 4 weeks and placed (two two-noded explants per flask) in separate flasks containing the same medium. These in turn produced 20 to 24 shoots per flask, from which additional subcultures were made. During these serial subcultures, no loss in proliferation rate was noted.

During preliminary experiments, two-noded explants from sprouted tuber stems did not proliferate as well as the seedling nodal explants when cultured under similar conditions. The highest number of $4 \mathrm{~cm}$ or longer shoots obtained ranged from 6 to 9 per flask (data not shown).

Internodal epicotyl explants used as controls failed to produce shoots. Although histological studies were not conducted to determine the origin of the buds, the above results indicate that apios does not have preformed buds along the epicotyl axis, except at the nodes, and that only pre-existing buds proliferated shoots in this protocol.

Similar systems for rapid in vitro clonal propagation have been reported in Solanum tuberosum (Hussey and Stacey, 1981; Rota et al., 1978), Phaseolus vulgaris (Martins and Sondahl, 1984; Saam et al., 1987), and Pisum sativum (Griga et al., 1986).

This micropropagation protocol, which is based entirely on axillary bud proliferation, apparently circumvents the formation of adventitious meristematic structures and thus could enable the production of genetically uniform plants. Such intensely proliferating explants of meristematic origin also represent a source of promising material for irradiation or chemical mutagenesis in vitro.

\section{Literature Cited}

Blackmon, W.J. and B.D. Reynolds. 1986. The crop potential of Apios americana -Preliminary evaluations. HortScience 21:1334-1336.

Griga, M., E. Tejklova, F.J. Novak, and M. Kubalakova. 1986. In vitro clonal propagation of Pisum sativum L. Plant Cell Tissue Organ Cult. 6:95-104.

Hussey, G. and N.J. Stacey. 1981. In vitro propagation of potato (Solanum tuberosum L.). Ann. Bot. 43:787-796.

Martins, I.S. and M.R. Sondahl. 1984. Axillary bud development from nodal cultures of bean seedlings (Phaseolus vulgaris). Turrialba 34:157161.
Murashige, T. and F. Skoog. 1962. A revised medium for rapid growth and bioassays with tobacco tissue culture. Physiol. Plant. 15:473497.

Reynolds, B.D., W.J. Blackmon, E. Wickremesinhe, M.H. Wells, and R.J. Constantine. 1990. Domestication of Apios americana, p. 436-442. In: J. Janick and H. Shands (eds.). Advances in new crops. Proc. First Natl. Symp. New Crops. Timber Press, Portland, Ore.

Roca, W.M., W.O. Espinoza, M.R. Roca, and J.E. Bryan. 1978. A tissue culture method for the rapid propagation of potatoes. Amer. Potato J. 55:691-701.

Saam, M.M., G.L. Hosfield, and J.W. Saunders. 1987. In vitro propagation of dry bean from seedling shoot tips. J. Amer. Soc. Hort. Sci. 112:852-855.

Wickremesinhe, E.R.M. 1988. In vitro regeneration and propagation systems for Apios americana Medikus. MS Thesis, Louisiana State Univ., Baton Rouge.

Wickremesinhe, E.R.M., W.J. Blackmon, and B.D. Reynolds. 1990. Adventitious shoot regeneration and plant production from explants of Apios americana. HortScience 25:1436-1439. 